\title{
Assisting Children with Autism Spectrum Disorder with Educational Mobile Apps to Acquire Language and Communication Skills: A Review
}

\author{
https://doi.org/10.3991/ijim.v15i06.20621 \\ Azham Hussain ${ }^{(凶)}$ \\ Universiti Utara Malaysia, Sintok, Malaysia \\ hussazhameyandex.com \\ Emmanuel O.C. Mkpojiogu \\ Universiti Utara Malaysia, Sintok, Malaysia \\ Veritas University, Abuja, Nigeria \\ Pauline Chiamaka Okoroafor \\ Veritas University, Abuja, Nigeria
}

\begin{abstract}
This systematic literature review was set out to review available literature on autism spectrum disorder and educational mobile apps with the aim of investigating available educational mobile app and how teachers can utilize these apps in assisting autistic children in acquiring language and communication skills. In order to achieve the aim of the study, the researchers employed a systematic method of investigation. Fifty papers in the areas of autism, educational apps and teaching method for autistic children were downloaded. Twenty-six were carefully selected because of their relevance to the study. The papers were analyzed and the result showed that there are available educational apps that are effective in helping autistic children in acquiring language and communication skills.
\end{abstract}

Keywords-Autism spectrum disorder, educational mobile apps, language and communication skills

\section{$1 \quad$ Introduction}

Autism Spectrum Disorder (ASD) as defined by Individuals with Disabilities Education Act, refers to "a developmental disability significantly affecting verbal and nonverbal communication and social interaction, generally evident before age three, that adversely affects a child's educational performance. Other characteristics often associated with autism are engaging in repetitive activities and stereotyped movements, resistance to environmental change or change in daily routines, and unusual responses to sensory experiences". [13] Observed that many children with autism also function in the mentally retarded range, but are different from children with uncomplicated mental retardation in the development of their social skills, communication and behaviours. 
According to World Health Organisation, 1 in 160 children worldwide have autism spectrum disorder (ASD). It begins in childhood and tends to persist into adolescence and adulthood. While some people with ASD can live independently, others have severe disabilities and require life-long care and support [32]. People with ASD are often subjected to stigma, discrimination and human rights violations [32]. Globally, access to services and support for people with ASD is inadequate. Available scientific evidence suggests that there are probably many factors that make a child more likely to have an ASD, including environmental and genetic factors. Interventions for people with ASD need to be accompanied by broader actions for making their physical, social and attitudinal environments more accessible, inclusive and supportive. Assistive technology, such as argumentative and alternative communication, can benefit people with autism by supporting and enhancing communication, promoting independence, and increasing social interactions [32].

A mobile app is a software application developed specifically for use on small, wireless computing devices, such as smartphones and tablets, rather than desktop or laptop computers [29] [17-20] [16]. Educational App for children with ASDs is developed for iOS and Android devices to focus on giving a solution to verbal communication problems, which can give children with ASD a useful way of communication and interaction with others [5]. Many children with ASD are visual learners and tend to be drawn towards computers, which makes e-learning systems a natural choice for them as static and dynamic images as well as videos can be incorporated as part of the learning process. According to [10] mobile devices should be seriously considered when seeking to acquire communication and social skills, as well as social behaviour improvements in people with ASD [11]. Educational App is created to help children with ASDs to improve their communication skills with others [5]. By using this app, children with ASDs can follow the process of learning by listening to the audio sound after interacting with the picture of the object. The app can also help their parents to understand the needs of their children because it can avoid any unwanted miscommunication [5]. According to research, there are nearly 700 mobile device apps listed on "Autism Apps" section on Autism Speaks website [3]. However, only a small portion of these apps labelled as having evidence were found to actually have any actual clinical evidence supporting their use or benefit. The vast majority of apps targeting Autism offered no clear indirect or direct evidence [22]. This paper is therefore set out to investigate educational apps available for autistic students and how teachers can utilize these apps in assisting ASD children to acquire language and communication skills [34-36].

The objectives of the study are: i) to discover available educational mobile apps for autistic children; ii) to discover ways school teachers can utilize educational mobile apps in assisting autistic student to acquire language and communication skills. These objectives are in response to the following research questions: i) what are the available educational apps for autistic children? and ii) how can educational mobile apps be utilized by school teachers in assisting children with ASD to acquire language and communication skills? This study is delimited to autistic children in schools and to mobile educational apps. 


\section{$2 \quad$ Literature Review}

A number of theories support the understanding of children with ASD. One is the Theory of the Mind which refers to the intuitive understanding of one's own and other people's minds or mental states which includes thoughts, beliefs, perceptions, knowledge, intentions, desires, and emotions and of how those mental states influence behaviour [2]. According to [6], difficulty in understanding other minds is a core cognitive feature of autism spectrum condition. People often speculate what is in other minds. This is important because it helps human beings to make sense of behaviour, and predict what that person might do next [6]. Baron-Cohen also stated that some autistic children suffer from moderate or severe degrees of mental learning difficulties suggesting that they have autistic plus more diffuse problems. The proportion of children with autism who also have learning difficulties is reported to be $65-75 \%$, with a corresponding $25-35 \%$ having intelligence (IQ) in the average or above average range [6]. [28] In his critique argued that the fundamental problem of the Theory of the Mind is its failure to account for the everyday experience of each one of us in our relationship with others.

Next is the Weak Central Coherence Theory which refers to the detail-focused processing style proposed to characterise autism spectrum disorders (ASD). The theory of Weak Central Coherence asserts that ASD is characterized by an imbalance in the integration of information at different levels; individuals with ASD see the parts rather than a whole and lack the cognitive capacity to integrate the parts into a whole [14]. [15] Reviewed research on the cognitive profiles of individuals with ASD. The findings from the research demonstrated a pattern in the cognitive profile of individuals with ASD. Frith demonstrated that individuals with ASD have small islets of ability, and they often performed well when context was unimportant and demonstrated skill at rote learning. Further, she argued that these factors are most successfully accounted for by the Theory of Central Coherence. [14] Found that the strengths and weaknesses of cognition in individuals with ASD all had a common denominator. Such individuals performed much better on tasks requiring attention to one piece of information than on tasks where they were required to pull together information [26]. Frith believed that other theories might account for the core deficits of individuals with ASDs, but could not account for their amazing strengths. For instance, some individuals with ASDs have "savant" skills -a remarkable ability in areas such as music, memory, or calculation. People on this spectrum tend to excel at focusing on extreme detail, and so are able to pick out a tiny element from a mass of complex data or objects. The notion of "weak central coherence" could explain both deficits and strengths. When a task required a person to extract global meaning from many details, to get the "big picture", people with ASDs would be at a major disadvantage. When picking out extreme detail from surrounding masses of information required, people with ASDs would be in a position to shine. They would be good at parts, but not at wholes.

Executive Functioning Theory is the next. It refers to a person's ability to process information. It includes skills such as: organizing, planning, paying attention, inhibiting inappropriate responses. Many people with autism have difficulty with executive functioning. They may have trouble with certain skills like planning, staying organized, 
sequencing information, and self-regulating emotions. Some people pay attention to minor details, but have trouble seeing how these details fit into a bigger picture. Others have trouble maintaining their attention in the classroom or other settings. When preparing to do a task, some may find it hard to organize their thoughts and actions in order to figure out what sequence of steps are needed. Executive functioning difficulties can also be associated with poor impulse control. Executive functioning issues can cause challenges in the classroom setting [4].

Many scholars have done research on the use of educational mobile apps in assisting children with ASD. Researches show that there are available educational apps that can help autistic children in acquiring language and communication skill and also how teachers can utilize these apps for effectiveness. [1], in their work entitled "AutiAid: A Learning Mobile Application for Autistic Children" discovered that autistic patients tend to respond well towards visual cues such as images or videos, which make it easier for concept processing. DISSERO, an application introduced to improve mental and social skills, shows how the learning process may be developed along with apt media attention towards the needs of autistic learners. This application provides a basic interface for the patient to select what they would like to perform, in terms of visualization. Providing a variety of necessary options such as learning and needs; it helps to branch out to the basic requirements of an autistic child. [8] in their work "Interactive Technologies for Autistic Children: A Review" focuses on two aims: i) to provide an overview of the recent ICT applications used in the treatment of autism and ii) to focus on the early development of imitation and joint attention in the context of children with autism as well as robotics. They discovered that ICT-based approaches and methods are used for the therapy and special education of children with ASD.

According to [24] using devices like tablets and other hand-held devices are useful tools, because they are flexible and portable unlike other dedicated Augmentative Alternative Communication (AAC) devices that often can be heavy and cumbersome. A hand-held device is easily carried and can promote peer acceptance. The touch screen and layout are more accessible for individuals with coordination or learning difficulties-sliding and tapping are easier than typing. Technology can improve communication with others by the timely use of email or texting, which has a cost and time savings. Technology allows for adaptability and motivation. Using an iPad as a Speech-Generating Device (SGD) may become a key to open the door of spontaneous, functional communication for students with ASD [33] A SGD provides speech that is generated by touching/pressing an icon, which may be a symbol or image on a communication device, resulting in the audible expression of the icon selected. It was found that children who were taught to use individual SGDs with line drawing symbols to represent messages such as "I want a snack, please," "more," and "I need help." with a naturalistic teaching procedure such as child-preferred stimuli, natural cues (e.g. expectant delays and questioning looks to elicit communication), and non-intrusive prompting techniques increased their interactions with classroom staff [33] in [30]. Picture Exchange Communication System (PECS) has been found effective in assisting children to acquire communication skills [23]. PECS involves teaching children to communicate via handing their partner a picture or symbol card which depicts the child's communicative intent [23] in [7]. 
In addition, [25] in their study "Use of iPad/iPods with Individuals with Autism and other Developmental Disabilities: A Meta-analysis of Communication Interventions" reviewed a total of 15 studies to determine the effectiveness of the intervention on communication skills. The results showed that tablet-based devices, especially iOS devices (i.e., iPad and iPod Touch) were highly effective in increasing the communication skills of individuals with autism and developmental disabilities. Also, the results provided evidence that several participants were able to continue communicating using the devices and to use them in novel contexts. Also, the findings show that systematic instructions are the most effective teaching methods in Augmentative and Alternative Communication (AAC) interventions [25] in their work entitled "Implementing TabletBased Devices to Improve Communication Skills of Students with Autism" proposed the following guidelines on how to assist students with ASD in acquiring communication skills based on their findings: there should be collaboration in gathering information about the student's abilities, health status, linguistic and paralinguistic skill, behavioural problem and cognitive abilities. Appropriate iPad and Augmentative and Alternative Communication (AAC) apps to help students with low vision should be selected. Limiting the icons for student with short attention span should be considered. Placing the iPad or iPod inside a case with sound amplifier should also be put into consideration. Checklist should be used in assessing the student's skills before moving to the other steps. Functional evaluation of Assistive Technology or the student Environment Task Technology Framework should also be used in the selection and implementation of iPad or iPod-based Speech Generating Device (SGD) intervention. [3] Also proposed a Systematic Instructional Methods in assisting children with ASD in acquiring communication skills. This is in line with [25] findings.

\section{Methodology}

In order to identify the existing literature that deals with autism spectrum disorder and educational apps, this study used a systematic literature review approach to search for the relevant works on the use of educational apps in assisting autistic children in acquiring language and communication skills. According to [19] "The strategy for conducting a systematic review is based on the selecting of search parameters carefully, writing of research questions, downloading primary articles, selecting related papers, extracting and summarizing information from them, and finally analysing results" [16].

Planning a Review: The aim of this phase is to collect important and appropriate data related to the study. The research used both primary and secondary data. These data were gotten from articles published by organizations, and academic journals. The articles were recent issues on Autism Spectrum Disorder and educational apps for language and communication skill intervention. The search was carried out employing the following search strings, inter alia: S1 ("Autism Spectrum Disorder") and S2 ("Educational Mobile Apps). Thus, the full string utilized in the review was: S1 AND S2. Secondary data were obtained in the course of primary search through citation and references. However, emphasis was given to recent studies ranging from the year 2003 to 2019. This provides current issues on autism and educational apps. However, there were 
also few theories on autism spectrum disorder which date between 1989 and 1995. Table 1 below describes the selected journals and conference proceedings.

Table 1. Selected Journals and Number of Papers

\begin{tabular}{|l|l|}
\hline \multicolumn{1}{|c|}{ Journals } & \multicolumn{1}{c|}{ Conference Proceedings } \\
\hline $\begin{array}{l}\text { Journal of Telecommunication, Electronic and } \\
\text { Computer Engineering. }\end{array}$ & $\begin{array}{l}\text { 2017 IEEE 19th International Conference on e- } \\
\text { Health Networking }\end{array}$ \\
\hline Journal of Applied Behaviour Analysis. & Applications and Services (Healthcom) \\
\hline Journal of Autism \& Developmental Disorders. & \\
\hline Journal of Technology in Behavioural Science. & \\
\hline Australasian Psychiatry Journal & \\
\hline Canadian Journal for New Scholars in Education. & \\
\hline
\end{tabular}

Table 2. Number of Papers per Journal

\begin{tabular}{|l|c|}
\hline \multicolumn{1}{|c|}{ Journals/Conference Proceedings } & Number of papers \\
\hline JTECE & 1 \\
\hline JABA & 1 \\
\hline JADD & 2 \\
\hline ELSEVIER & 4 \\
\hline JTBS & 1 \\
\hline SAGEJ & 1 \\
\hline IEEE & 1 \\
\hline ASJ & 1 \\
\hline CJNSE & 1 \\
\hline Total & 13 \\
\hline
\end{tabular}

Table 2 shows the total number of papers gotten from journals and conference proceedings. These papers were carefully selected due to their relatedness to the study.

Table 3. List of the Selected Paper

\begin{tabular}{|l|l|l|}
\hline \multicolumn{1}{|c|}{ Paper ID } & \multicolumn{1}{|c|}{ Authors } & Year \\
\hline AE1 & Aburukba, R, et al. & 2017 \\
\hline AE2 & Alic, M. & 2009 \\
\hline AE3 & Alzrayer, N., \& Banda, D. & 2017 \\
\hline AE4 & Aziz, M, et al & 2014 \\
\hline AE5 & Bondy, A., \& Frost, A. & 2003 \\
\hline AE6 & Boucenna, S, et al. & 2014 \\
\hline AE7 & Fiktorius, T. & 2013 \\
\hline AE8 & Hussain, A, et al. & 2016 \\
\hline AE9 & Kim, J, et al. & 2018 \\
\hline AE10 & Koegel, L, et al. & 2011 \\
\hline AE11 & Lofland, K. & 2019 \\
\hline AE12 & lzrayer, N, et al. & 2014 \\
\hline AE13 & Pennington, B. & 1997 \\
\hline AE14 & Rouse, M. & 2013 \\
\hline AE15 & Schepis, M, et al. & 1998 \\
\hline AE16 & Shane, H, et al. & 2012 \\
\hline
\end{tabular}




\begin{tabular}{|l|l|l|}
\hline AE17 & Xin, J., \& Leonard, D. & 2014 \\
\hline AE18 & Alzrayer, N et al & 2014 \\
\hline AE19 & WHO. & 2019 \\
\hline AE20 & Baron-Cohen. & 2001 \\
\hline AE21 & Plasow. & 2012 \\
\hline AE22 & Frith \& Happ & 1994 \\
\hline AE23 & Frith. & 1989 \\
\hline AE24 & Ogle. & 2009 \\
\hline AE25 & Crespo \&Martin & 2018 \\
\hline AE26 & Barranco-Mendoza et al & 2004 \\
\hline
\end{tabular}

Table 3 shows a complete list of selected papers apart from three articles published by organizations. These selected papers spanned from 2003 to 2019, with only two papers dating 1997 and 1998. These papers provided theories and a good coverage of articles on autism and educational apps, collated after a keen selection from the fifty downloaded papers on the review's subject matter.

Table 4. Assistive Educational Mobile Apps and Devices for Autistic Children

\begin{tabular}{|l|l|c|}
\hline \multicolumn{1}{|c|}{ App type } & \multicolumn{1}{c|}{ Studies } & Percentage \\
\hline iOS devices (iPad, iPod) & AE4, AE3, AE17, AE18 & $44.44 \%$ \\
\hline DISSERO & AE1 & $11.11 \%$ \\
\hline AAC & AE3, AE11 & $22.22 \%$ \\
\hline PECS & AE10 & $11.11 \%$ \\
\hline Smart phone/tablet & AE14 & $11.11 \%$ \\
\hline
\end{tabular}

\section{$4 \quad$ Discussion of Findings}

The selected papers were carefully reviewed and the results were generated. The result shows that there are available educational mobile apps that can assist autistic children in developing communication and language skills. The frequency of occurrence of these apps in literature include: iOS devices (iPad, iPod) based apps (44.44\%). This is followed by AAC (22.22\%). DISSERO is another educational app that has proved effective in helping autistic children in acquiring language and communication skills $(11.11 \%)$. It has the same percentage with PECS, and Smart phone/tablet. From the review, iOS devices which include iPad and iPod is considered as the most effective educational device that for language and communication skill of autistic children. The study also discovered that systematic instruction method is the best method teachers should adopt in helping autistic children to acquire language and communication skills.

\section{$5 \quad$ Conclusion and Future Work}

This systematic review of literature investigated the availability of educational mobile apps for autistic children and ways school teachers can utilize educational mobile apps in assisting autistic student to acquire language and communication skills. The result showed that there are available educational mobile apps and devices that can help 
autistic children to acquire language and communication skills. The apps/devices include: iOS devices (iPad, iPod), Augmentative alternative communication (AAC), Picture Exchange Communication System (PECS), Smartphone/tablet. The result showed that iOS devices such as iPad and iPod are more effective because of their flexibility and portability. Systematic instruction method in the use of iOS devices is recommended for teachers in order to help autistic children to acquire language and communication skills. The result of this review will help teachers in the following ways: a) how to select educational mobile app that will help autistic children to acquire language and communication skills; b) how iOS devices such as iPads and iPod can be effectively used to enhance language and communication skill for autism children; and c) ways in which autistic children can be taught to use educational mobile app for language and communication skills. The result will also help researchers on how to carry out a systematic review of literature and how the result can be applied to their field. Though the fewness of the download limited the findings of the study, the results obtained however were insightful.

\section{$6 \quad$ References}

[1] Aburukba, R., Aloul, F., Mahmoud, A., Kamili, K., \& Ajmal, S. (2017). AutiAid: A Learning Mobile Application for Autistic Children. Dalian, China: IEEE Xplore Digital Library. https://doi.org/10.1109/healthcom.2017.8210788

[2] Alic, M. (2009). Theory of Mind. Retrieved May 16, 2019, from https://successforkidswithhearingloss.com/wp-content/uploads/2014/02/Theory-of-Mind-article.pdf

[3] Alzrayer, N., \& Banda, D. (2017). Implementing Tablet-Based Devices to Improve Communication Skills of Students with Autism. SAGE Journals, 53(1), 50-57. https://doi.org/10. $1177 / 1053451217692569$

[4] Autism. (2019). Retrieved May 8, 2019, from https://www.specialeducationguide.com/disability-profiles/autism/

[5] Aziz, M., Abdullah, S., Adnan, S., \& Mazalan, L. (2014). Educational App for Children with Autism Spectrum Disorders (ASDs). Elsevier Journal, 42nd ser: 70-77. https://doi.org/10. 1016/j.procs.2014.11.035

[6] Baron-Cohen, S. (2001). Theory of mind and autism: A review. Elsevier Journal, 23(2000): 169-184.

[7] Bondy, A., \& Frost, A. (2003). Communication strategies for visual learners. In O. I. Lovaas (Ed.), Teaching individuals with developmental delays: Basic intervention techniques Austin, TX: Pro-Ed. 291-304.

[8] Boucenna, S., Narzisi, A., Tilmont, E., \& Muratori, F. (2014). Interactive Technologies for Autistic Children: A Review. Cognitive Computation International Peer-reviewed Scientific Journal. 6(4). https://doi.org/10.1007/s12559-014-9276-x

[9] Cognitive Theories Explaining ASD: Theory of Mind and Autism. (n.d.). Retrieved June 2, 2019, from https://iancommunity.org/cs/understanding_research/cognitive theories_explaining_asds

[10] Crespo, F., \& Martin, E. (2018). Applications for mobile devices focused on support for autism spectrum disorder population and / or people in their immediate environment in their daily lives: A systematic and practical review from a Spanish-speaking perspective. Retrieved May 21, 2019, from https://arxiv.org/ftp/arxiv/papers/1806/1806.01041.pdf

[11] Crespo, F., \& Martin, E. (2018). Applications for mobile devices focused on support for autism spectrum disorder population and / or people in their immediate environment in their 
daily lives: A systematic and practical review from a Spanish-speaking perspective. Retrieved May 21, 2019, from https://arxiv.org/ftp/arxiv/papers/1806/1806.01041.pdf

[12] Explanatory Theories on Autistic Spectrum Disorder (ASD). (2016). Retrieved May 24, 2019, from https://www.autisme.com/autism/explanatory-theories-on-asd.html\#teoria_primera

[13] Fiktorius, T. (2013). Language Development and Classroom Instruction for Children with Autism.

[14] Frith, U., \& Happe, F. (1994). Autism: Beyond "theory of mind". Elsevier Journal. 50(1994): 115-132. https://doi.org/10.1016/0010-0277(94)90024-8

[15] Frith, U., 1989. Autism: Explaining the Enigma. Blackwell, Oxford

[16] Hussain, A., Mkpojiogu, E.O.C., \& Kamal, F.M. (2016). A systematic review on usability evaluation methods in m-commerce apps. Telecommunication, Electronic \& Computer Engineering (JTEC). 8(10): 29-34

[17] Hussein, I., Hussain, A., Mkpojiogu, E.O.C., \& Nathan, S.S. (2019). The state of user experience design practice in Malaysia. International Journal of Innovative Technology and Exploring Engineering, 8(8S): 491-497.

[18] Hussain, A., Hussein, I., Mkpojiogu, E.O.C., \& Sarlan, A. (2019). The state of user experience design (UXD) practice in Malaysia: an in-situ interview approach. International Journal of Innovative Technology and Exploring Engineering. 8(8S): 498-505.

[19] Hussain, A., \& Mkpojiogu, E.O.C. (2017). Predicting the perceived worth of software products requirements with customer satisfaction. Advanced Science Letters. 23(5): 4269-4273. https://doi.org/10.1166/asl.2017.8245

[20] Hussain, A., Mkpojiogu, E.O.C., \& Nawi, M.N.M. (2017). Capturing customer satisfaction and dissatisfaction in software requirements elicitation for features in proposed software systems. Journal of Engineering and Applied Sciences (JEAS), 12(21): 5590-5597

[21] Hussain, A., Mkpojiogu, E.O.C. \& Yusof, M.M (2016). Perceived usefulness, perceived ease of use, and perceived enjoyment as drivers for the user acceptance of interactive mobile maps. Proceedings of the $1^{\text {st }}$ International Conference on Applied Science and Technology (ICAST'16), Kedah, Malaysia. AIP Conf. Proc. 1761(1): 020051, https://doi.org/10.1063/ 1.4960891

[22] Kim, J., Nguyen, T., Gipson, S., Shin, A., \& Torous, J. (2018). Smartphone Apps for Autism Spectrum Disorder - Understanding the Evidence. Journal of Technology in Behavioral Science. 3(1): 1-4.

[23] Koegel, L., Matos-Fredeen, R., Lang, R., \& Koegel, R. (2011). Interventions for Children with Autism Spectrum Disorders in Inclusive School Settings. Elsevier Journal. 20: 1-12. https://doi.org/10.1016/j.cbpra.2010.11.003

[24] Lofland, K. (2019). The Use of Technology in Treatment of Autism Spectrum Disorders. Retrieved May 15, 2019, from https://www.iidc.indiana.edu/pages/the-use-of-technologyin-treatment-of-autism-spectrum-disorders

[25] lzrayer, N., Banda, D., \& Koul, R. (2014). Use of iPad/iPods with Individuals with Autism and other Developmental Disabilities: A Meta-analysis of Communication Interventions. Retrieved June 6, 2019, from https://www.researchgate.net/publica$\underline{\text { tion/272013822 Use of iPadiPods with Individuals with Autism and other Develop- }}$ mental_Disabilities_A_Meta-analysis_of_Communication_Interventions. https://doi.org/10.1007/s40489-014-0018-5

[26] Ogle, K. (2009). Theories of Autism: A Review of Four Contemporary Theories. Canadian Journal for New Scholars in Education. 2(1): 1-11.

[27] Pennington, B. F., Rogers, S. J., Bennetto, L., Griffith, E. M., Reed, D. T., \& Shyu, V. (1997). Validity tests of the executive dysfunction hypothesis of autism. In J. Russell (Ed.), Autism as an executive disorder. Oxford: Oxford University Press. 143-178. https://doi. org/10.1093/med:psych/9780198523499.003.0005 
[28] Plastow, M. (july 2012). Theory of mind II: Difficulties and critiques. Australasian Psychiatry Journals. 20(4): 291-294. https://doi.org/10.1177/1039856212449670

[29] Rouse, M. (2013). Mobile app. Retrieved May 9, 2019, from https://whatis.techtarget.com/definition/mobile-app

[30] Schepis, M. M., Reid, D. H., Behrmann, M. M., \& Sutton, K. A. (1998). Increasing communicative interactions of young children with autism using a voice output communication aid and naturalistic teaching. Journal of Applied Behavior Analysis. 31(4): 561-78. https://doi.org/10.1901/jaba.1998.31-561

[31] Shane, H., Laubscher, E., Schlosser, R., Flynn, S., Sorce, J., \& Abramson, J. (2012). Applying technology to visually support language and communication in individuals with autism spectrum disorders. Journal of Autism \& Developmental Disorders. 42(6): 1228-1235. https://doi.org/10.1007/s10803-011-1304-z

[32] WHO (2019) Autism spectrum disorders. Retrieved May 12, 2019, from https://www.who.int/news-room/fact-sheets/detail/autism-spectrum-disorders

[33] Xin, J., \& Leonard, D. (2014). Using iPads to Teach Communication Skills of Students with Autism. Journal of Autism and Developmental Disorders. 45(12). https://doi.org/10. 1007/s10803-014-2266-8

[34] Vasiliki Bravou, Athanasios S. Drigas. (2019). A Contemporary View on Online and Web Tools for Students with Sensory \& Learning Disabilities. International Journal of Online and Biomedical Engineering. 15(12): 97-105. https://doi.org/10.3991/ijoe.v15i12.10833

[35] Agathi Stathopoulou, Dionisis Loukeris, Zoe Karabatzaki, Evangelia Politi, Yolanda Salapata, Athanasios Drigas. (2020). Evaluation of Mobile Apps Effectiveness in Children with Autism Social Training via Digital Social Stories. International Journal of Interactive Mobile Technologies. 14(3): 4-18. https://doi.org/10.3991/ijim.v14i03.10281

[36] Chara Papoutsi, Athanasios S. Drigas, Charalabos Skianis. (2018). Mobile Applications to Improve Emotional Intelligence in Autism - A Review. International Journal of Interactive Mobile Technologies. 12(6): 47-61. https://doi.org/10.3991/ijim.v12i6.9073

\section{Authors}

Azham Hussain is the Associate Professor of Software Engineering at School of Computing, Universiti Utara Malaysia,06010 UUM, Kedah, Malaysia. He is the founder of Human-Centered Computing Research Group, which is affiliated with the Software Technology Research Platform Center at School of Computing, Universiti Utara Malaysia. Azham Hussain is a member of the US-based Institute of Electrical and Electronic Engineers (IEEE), and actively involved in both IEEE Communications and IEEE Computer societies. hussazham@yandex.com

Emmanuel O.C. Mkpojiogu is a Lecturer at Department of Computer and Information Technology, Veritas University, Abuja, Nigeria. Currently, he is a PhD student at School of Computing, Universiti Utara Malaysia. The research area is User Experience, Human Computer Interaction and Software Engineering. He has published many articles in reputable Scopus indexed journals. emelnuel@ hotmail.com

Pauline Chiamaka Okoroafor is a scholar with the Department of Art and Social Science Education, Faculty of Education, Veritas University, Abuja, Nigeria. paulineokoroafor@gmail.com

Article submitted 2020-11-13. Resubmitted 2021-01-05. Final acceptance 2021-01-08. Final version published as submitted by the authors. 